\title{
Pelatihan Rekayasa Lampu LED 220V menjadi Lampu LED 12V untuk Penerangan di Dusun Buani
}

\author{
Ida Bagus Fery Citarsa*, I Nyoman Wahyu Satiawan, Supriono, \\ I Made Budi Suksmadana, I Ketut Wiryajati, Cipta Ramadhani
}

Jurusan Teknik Elektro, Universitas Mataram, Mataram, Indonesia

Kata Kunci:

lampu,

keselamatan, jalan, dusun

\begin{abstract}
Abstrak: Dusun Buani merupakan salah satu dusun yang berada di wilayah Desa Bentek, Kecamatan Gangga, Kabupaten Lombok Utara.Sebagian jalan menuju dusun tersebut berupa jalan kecil dengan sebelah sisinya merupakan jurang dengan kedalaman lebih dari 4 meter. Jalan menuju dusun tersebut juga belum dilengkapi dengan penerangan jalan umum. Kedua hal tersebut menyebabkan lalu lintas kendaraan menuju dusun tersebut menjadi rawan terhadap kecelakaan terutama di malam hari.Untuk itu perlu dilakukan pemasangan lampu penerangan jalan umum di dusun tersebut. Permasalahan lainnya adalah keterbatasan suplai tenaga listrik dari PLN ke Dusun Buani pada saat malam hari. Untuk itu maka digunakan jenis lampu penerangan yang dapat disuplai menggunakan sumber tenaga listrik dari panel sel surya atau baterai $12 \mathrm{~V}$. Lampu LED $12 \mathrm{~V}$ adalah lampu yang dapat menerima suplai dari baterai $12 \mathrm{~V}$. Di pasaran lampu LED 12V ini jarang tersedia karena instalasi listrik pengguna umumnya menggunakan tegangan AC $220 \mathrm{~V}$. Untuk mengatasi permasalahan tersebut maka perlu dilakukan pelatihan rekayasa mengubah lampu LED $220 \mathrm{~V}$ menjadi lampu LED 12V bagi warga Dusun Buani.Untuk memenuhi tujuan tersebut, tim pelaksana pengabdian kepada masyarakat yang beranggotakan staf pengajar Jurusan Teknik Elektro Fakultas Teknik Universitas Mataram telah melaksanakan kegiatan pelatihan rekayasa lampu $220 \mathrm{~V}$ menjadi $12 \mathrm{~V}$ dan penggunaan lampu $12 \mathrm{~V}$ untuk penerangan kepada warga Dusun Buani. Hasil evaluasi menunjukkan bahwa warga telah dapat mempraktekkan hasil pelatihan sehingga dapat memberikan manfaaat berupa peningkatan keamanan dan keselamatan bagi pengguna jalan di Dusun Buani, khususnya pada saat malam hari.
\end{abstract}

Korespondensi: gusmanperi@yahoo.com

\section{PENDAHULUAN}

Dusun Buani merupakan salah satu Dusun yang berada di wilayah Desa Bentek (Sugeng, 2016). Desa Bentek adalah desa yang terletak $5 \mathrm{Km}$ dari Ibu Kota Kecamatan Gangga dan Ibu Kota Kabupaten. Luas wilayah Desa Bentek adalah 3727,586 Ha. Saat ini, mulai dicanangkan pengembangan pariwisata dengan usaha pengelolaan wisata alam mengingat di bumi Bentek banyak sekali destinasi wisata yang layak dikembangkan. Gerakan taktis yang ditempuh pemerintahan Desa Bentek untuk mewujudkan pengembangan objek wisata tersebut adalah membentuk Kelompok Sadar Wisata (POKDARWIS) di setiap dusun, hingga kini sudah terbentuk 3 Pokdarwis.

Wisata unggulan yang terdapat di Dusun Buani Desa Bentek adalah wisata Paralayang (BPMBD Provinsi NTB, 2016). Namun infra struktur untuk menuju ke lokasi tersebut belum menunjang seperti ketiadaan lampu penerangan jalan umum. Keterbatasan kapasitas tenaga listrik dari PLN dan letak geografis dusun Buani yang terletak didaerah perbukitan/dataran 
tinggi mengakibatkan belum tersedianya penerangan jalan umum di sepanjang jalan dusun tersebut.

Jalanan menuju dusun Buani yang menurun dengan sebelah sisinya merupakan jurang dengan kedalaman lebih dari 4 meter menyebabkan lalu lintas di dusun tersebut menjadi rawan terhadap kecelakaan terutama dimalam hari. Untuk mengurangi resiko kecelakaan baik untuk warga maupun tamu/wisatawan maka perlu dilakukan pemasangan lampu penerangan jalan umum di dusun tersebut sehingga resiko terjadinya kecelakaan pada malam hari dapat dihindari.

Mengingat keterbatasan suplai tenaga listrik dari PLN ke Dusun Buani, maka sebagai alternatifnya dapat digunakan jenis lampu penerangan yang dapat disuplai menggunakan sumber tenaga listrik dari panel sel surya atau baterai $12 \mathrm{~V}$. Pada siang hari sel surya atau sumber PLN akan dapat digunakan untuk mengisi baterai $12 \mathrm{~V}$, sementara di malam hari baterai $12 \mathrm{~V}$ tersebut dapat menjadi sumber tenaga listrik bagi lampu yang digunakan untuk penerangan jalan umum.

Adapun lampu yang dapat mempergunakan sumber tenaga listrik dari baterai $12 \mathrm{~V}$ adalah lampu LED 12V. Di pasaran jarang dijumpai lampu LED 12V karena yang banyak dijual adalah lampu LED 220V, sehingga untuk tetap dapat menggunakan lampu LED 220V yang banyak dijual di pasaran maka diperlukan usaha untuk rekayasa mengubah lampu LED 220V menjadi lampu LED 12V (Sandi, 2016).

Pertimbangan lainnya menggunakan lampu LED 12V sebagai lampu penerangan jalan adalah pertimbangan dari sisi keamanan. Jika lampu tersebut mengalami masalah maka masyarakat setempat dapat langsung menanganinya tanpa takut terkena tegangan listrik sebesar $220 \mathrm{~V}$. Tegangan $12 \mathrm{~V}$ tidak mengakibatkan kejutan listrik yang berbahaya bagi manusia. Pertimbangan lainnya adalah rangkaian lampu LED tersebut menjadi adalah rangkaian yang cukup sederhana sehingga masyarakat dapat membuat sendiri lampu LED $12 \mathrm{~V}$.

Selain dari sisi keamanan, dengan menggunakan lampu LED 12V maka tingkat efisiensi penggunaan baterai $12 \mathrm{~V}$ menjadi lebih tinggi. Hal ini karena lampu LED $12 \mathrm{~V}$ dapat dicatu langsung melalui baterai tanpa memerlukan inverter dan rangkaian penaik tegangan. $\mathrm{Hal}$ ini berarti daya yang disalurkan dari baterai $12 \mathrm{~V}$ tidak akan terbuang menjadi rugi-rugi pada rangkaian inverter dan juga rangkaian penaik tegangan. Dampak positifnya adalah efisiensi baterai menjadi lebih tinggi dibandingkan dengan menggunakan lampu LED 220V.

Untuk mengatasi masalah yang dihadapi oleh masyarakat di Dusun Buani, Desa Bentek, Kecamatan Gangga, Kabupaten Lombok Utara yang berkenaan dengan kerawanan lalu lintas akibat belum tersedianya penerangan jalan umum di Dusun Buani maka solusi yang ditawarkan adalah pemasangan lampu LED $12 \mathrm{~V}$ sebagai lampu untuk penerangan jalan umum. Digunakannya lampu LED $12 \mathrm{~V}$ karena dapat disuplai dari sumber tenaga listrik baterai $12 \mathrm{~V}$ dan panel sel surya. Lampu LED $12 \mathrm{~V}$ ini diperoleh dengan jalan merekayasa lampu LED 220V karena lampu LED 220V lebih banyak tersedia di pasaran. Untuk itu perlu diadakan pelatihan bagi masyarakat Dusun Buani untuk dapat merekayasa lampu LED 220V menjadi lampu LED $12 \mathrm{~V}$. 


\section{METODE KEGIATAN}

Metode yang dilakukan dalam kegiatan pengabdian kepada masyarakat di Dusun Buani, Desa Bentek, Kecamatan Gangga, Kabupaten Lombok Utara, Propinsi Nusa Tenggara Barat ini terdiri dari tiga tahapan, antara lain:

\section{a. Tahap persiapan}

1. Kunjungan ke masyarakat yang akan diberi pelatihan.

2. Penetapan jadwal kegiatan pelatihan bersama masyarakat tersebut.

3. Pengumpulan materi pelatihan

4. Pembagian materi pelatihan pada setiap anggota pelaksana PPM

\section{b. Tahap pelaksanaan}

1. Pelatihan pengenalan lampu LED di Dusun Buani.

2. Pelatihan merekayasa lampu LED $220 \mathrm{~V}$ menjadi Lampu LED $12 \mathrm{~V}$ di Dusun Buani.

3. Pelatihan penggunaan Lampu LED 12V di Dusun Buani.

\section{c. Tahap evaluasi}

1. Kunjungan ke masyarakat untuk mengetahui hasil pelatihan di Dusun Buani

2. Membuat laporan hasil pelaksanaan PPM.

\section{HASIL DAN PEMBAHASAN}

Hasil yang diperoleh dalam kegiatan pengabdian kepada masyarakat di di Dusun Buani, Desa Bentek, Kecamatan Gangga, Kabupaten Lombok Utara, Propinsi Nusa Tenggara Barat ini terdiri dari tiga tahapan hasil, antara lain: tahap persiapan, tahap pelaksanaan, dan tahap evaluasi.

\section{Tahap Persiapan}

Sesuai dengan pendekatan/metode pelaksanaan kegiatan yang telah direncanakan maka kegiatan pengabdian pada masyarakat ini diawali dengan melakukan kunjungan ke masyarakat yang akan diberi pelatihan yaitu dengan mengunjungi kediaman Ketua Banjar Buani di Dusun Buani, Desa Bentek, Kecamatan Gangga, Lombok Utara. Di pertemuan tersebut, tim pelaksana sebelumnya menyampaikan rencana kegiatan pengabdian pada masyarakat kepada pihak Banjar Buani di Dusun Buani tersebut agar mendapatkan persetujuan untuk mengadakan kegiatan pelatihan ini. Langkah selanjutnya dilakukan wawancara kepada Ketua Banjar Buani di Dusun Buani terkait karakter masyarakat di lingkungan tersebut terutama terkait dengan kondisi social, ekonomi dan pendidikan masyarakat di sana. Diperoleh keterangan bahwa kondisi social, ekonomi dan pendidikan masyarakat di sana rata-rata menengah ke bawah maka bahasa pelatihan yang digunakan agar lebih sederhana. Selain itu dilakukan pula pembahasan mengenai hari dan jam kegiatan pelatihan bersama Kepala Dusun Buani tersebut.

\section{Tahap pelaksanaan}

Pada hari yang telah disepakati antara tim pelaksana dengan pihak Ketua Banjar Buani di Dusun Buani, Desa Bentek, akhirnya kegiatan pelatihan ini dilaksanakan di kediaman Ketua Banjar Buani tersebut. Setelah acara sambutan dari kedua belah pihak, pelatihan dimulai dengan penyampaian materi pelatihan kepada warga Dusun Buani yang terdiri dari: 
1. Pelatihan pengenalan lampu LED di Dusun Buani.

2. Pelatihan merekayasa lampu LED 220V menjadi Lampu LED 12 V di Dusun Buani.

3. Pelatihan penggunaan Lampu LED $12 \mathrm{~V}$ di Dusun Buani.

Pelatihan pertama adalah tentang pengenalan bagian-bagian dan prinsip kerja lampu LED.

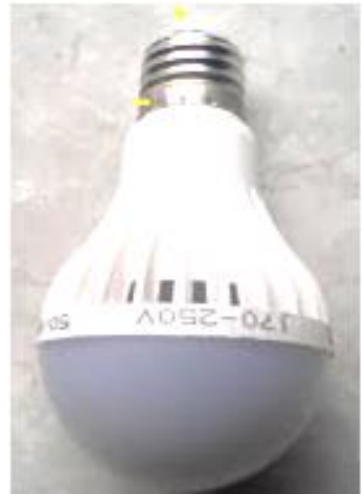

(a)

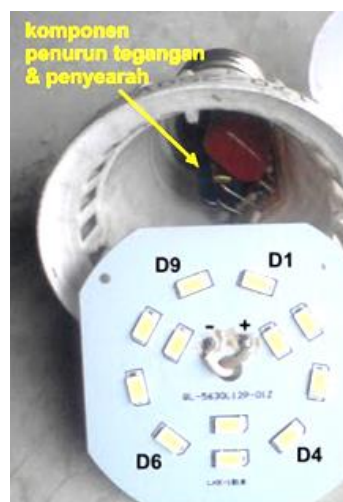

(b)

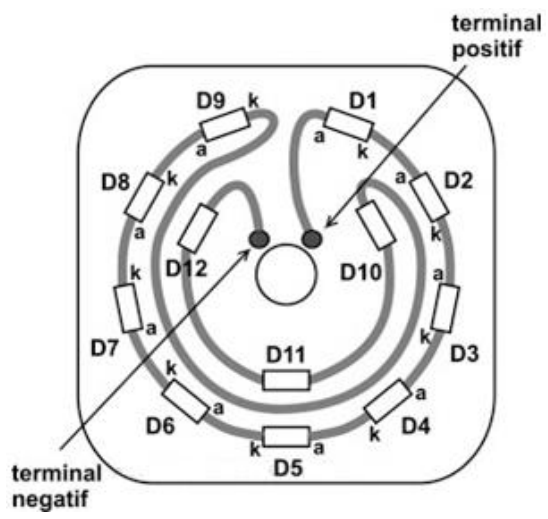

(c)

Gambar 1. Lampu LED (Sandi, 2016)

Pada Gambar 1(a) dan (b) diperlihatkan lampu LED sebelum dan setelah dibuka tutupnya. Pada Gambar 1(b) menunjukkan bahwa di dalam lampu tersebut terdapat 12 LED menempel melingkar sedemikian rupa. LED sendiri merupakan singkatan dari Light Emitting Diode yang artinya diode yang dapat memancarkan sinar apabila diberi tegangan listrik. Pada Gambar 1(c) memperlihatkan bahwa sebenarnya terdapat alur-alur sambungan antara satu LED dengan LED lainnya, tetapi karena tertutup pelapis berwarna putih maka alur-alur itu jadi tersamar.

Prinsip kerja lampu LED adalah lampu ini sebenarnya dapat disuplai dengan tegangan rendah DC $12 \mathrm{~V}$, karena LED tetap menyala dengan suplai tegangan DC rendah. Karena instalasi rumah umumnya menggunakan tegangan AC $220 \mathrm{~V}$, maka pada lampu LED yang dijual di pasaran ditambahkan peralatan penurun tegangan $\mathrm{AC}$ dari $220 \mathrm{~V}$ ke 12 dan penyearah dari tegangan AC $12 \mathrm{~V}$ menjadi DC $12 \mathrm{~V}$. LED-LED ini berbentuk persegi pipih, disusun seri agar dapat disuplai dengan tegangan yang lebih tinggi dari $12 \mathrm{~V}$.

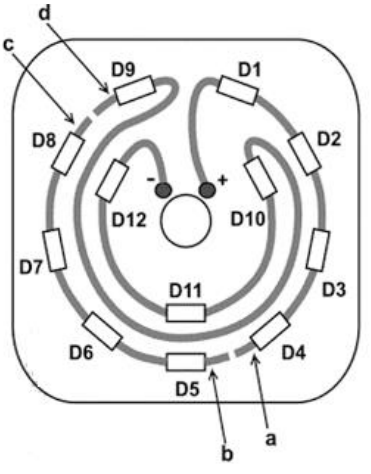

(a)

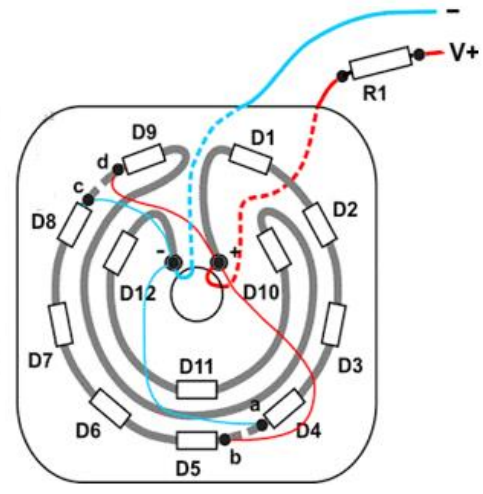

(b)

Gambar 2. Langkah merekayasa lampu LED 220V menjadi Lampu LED 12 V (Sandi, 2016). 
Pelatihan selanjutnya adalah pelatihan merekayasa lampu LED 220V menjadi Lampu

LED 12 V. Menggunakan Gambar 2, berikut adalah langkahnya (Sandi, 2016):

1. Lepaskan bagian papan tempat LED menempel dari kabel sambungannya (terminal positif dan negatifnya).

2. Cabut/keluarkan rangkaian penurun dan penyearah tegangan yang ada di dalam lampu. Rangkaian ini tidak akan dipakai lagi.

3. Putuskan alur sambungan antara LED D4 dan D5.

4. Gunakan ujung obeng testpen, gunting kecil atau yang lainnya untuk menggurat-gurat alur sambungan itu hingga tidak lagi tersambung.

5. Pastikan bahwa ia memang tidak lagi tersambung dengan men-check-nya menggunakan AVO (multi) meter.

6. Jika sudah, tandai dua bagian yang telah terputus itu sebagai titik a dan b seperti ditunjukkan pada Gambar 2(a).

7. Buat hal serupa pada alur sambungan antara D8 dan D9, lalu tandai dua bagian yang telah terputus sebagai titik c dan d seperti ditunjukkan pada Gambar 2(a).

8. Siapkan beberapa potongan kabel halus/kabel kecil, lalu ambil salah satu potongan kabel dan solderkan satu ujungnya di titik a dan ujung lainnya di terminal negatif, seperti ditunjukkan pada Gambar 2(b).

9. Solderkan ujung potongan kabel lainnya, satu di titik b dan satunya lagi di terminal positif seperti ditunjukkan pada Gambar 2(b).

10. Setelah itu buat lagi sambungan serupa, yaitu antara titik c dengan terminal negatif, dan titik d dengan terminal positif seperti ditunjukkan pada Gambar 2(b).

11. Sambungkan dengan menyolderkan lagi sepotong kabel dari terminal positif ke ujung kepala koneksi lampu. Dan dari terminal negatif ke kepala koneksi lampu bagian yang berulir seperti ditunjukkan pada Gambar 2(b).

12. Sebuah resistor (R1) $4,7 \Omega$ dapat dipasang pada kabel sambungan dari terminal positif dan dibungkus dengan isolator.

13. Hasilnya diperoleh sebuah lampu LED DC $12 \mathrm{~V}$ dengan ujung kepala koneksi lampu sebagai koneksi positif (disambungkan ke positif aki/baterai) dan kepala koneksi bagian yang berulir sebagai koneksi negatif (disambungkan ke negatif aki/baterai).

Pelatihan terakhir adalah pelatihan penggunaan Lampu LED 12V dengan sumber dari baterai $12 \mathrm{~V}$ dengan langkah sebagai berikut :

1. Perhatikan indikator charging baterai agar menunjukkan bahwa baterai sudah terisi penuh (minimal 80\%) untuk durasi suplai listrik ke lampu yang lebih lama.

2. Pasangkan lampu pada fitting dan hubungkan konduktor penghubung pada terminal baterai.

3. Nayalakan lampu dengan menekan saklar pada konduktor penghubung posisi ON dan demikian sebaliknya.

4. Apabila indikator baterai menunjukkan terisi tinggal sedikit (minimal 10\%) hentikan untuk mensuplai arus ke lampu agar baterai dapat berusia pakai lebih lama.

Setelah tim pelaksana kegiatan pengabdian pada masyarakat menyampaikan materinya pelatihan, maka acara selanjutnya adalah sesi tanya jawab antara peserta pelatihan dengan tim pelaksana terkait dengan isi materi pelatihan yang baru saja disampaikan. 

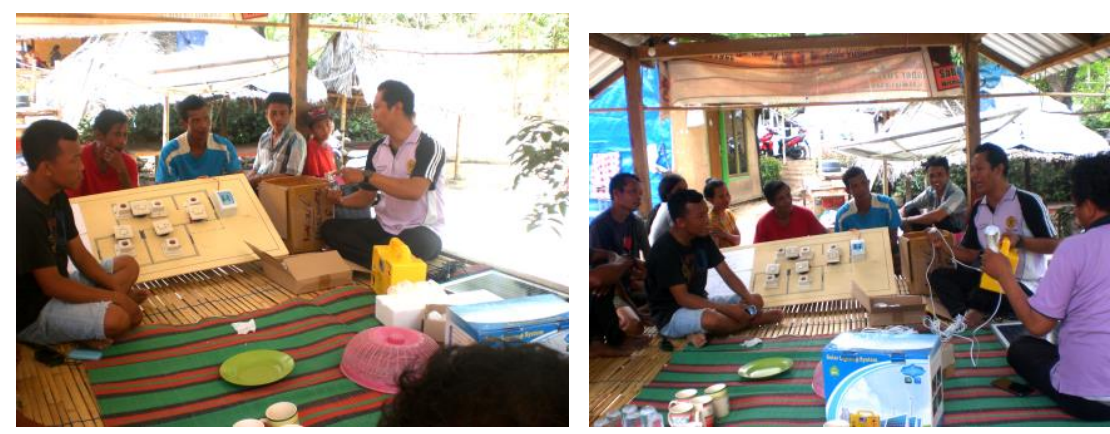

Gambar 3. Dokumentasi pelaksana pengabdian memberikan materi pelatihan kepada warga

\section{Tahap evaluasi}

Untuk tahap terakhir yaitu evaluasi dilaksanakan dengan kunjungan lapangan untuk mengetahui hasil pelatihan terkait kemampuan melakukan rekayasa lampu $220 \mathrm{~V}$ menjadi 12 $\mathrm{V}$ serta penggunaannya untuk penerangan jalan umum di Dusun Buani. Selain itu juga wawancara kepada Dusun Buani mengenai penggunaan peralatan yang telah dihibahkan untuk mengetahui kelancaran penggunaan peralatan dan manfaat yang diperoleh. Berdasarkan hasil jawaban dari beberapa warga masyarakat diperoleh hasil bahwa warga telah dapat mempraktekkan rekayasa lampu $220 \mathrm{~V}$ menjadi $12 \mathrm{~V}$ dan menggunakan lampu 12 $\mathrm{V}$ yang disuplai dari baterai $12 \mathrm{~V}$ untuk penerangan jalan umum di Dusun Buani sehingga dapat memberikan manfaaat berupa peningkatan keamanan dan keselamatan bagi pengguna jalan di Dusun Buani pada saat malam hari. Dari hasil evaluasi ini dapat dikatakan bahwa pelatihan yang telah dilakukan telah berhasil untuk memberikan tambahan pengetahuan kepada Dusun Buani mengenai kedua hal tersebut di atas sebagai bagian dari ilmu pengetahuan yang dimiliki oleh tim pelaksana kepada masyarakat untuk pemenuhan salah satu Tri Dharma Perguruan Tinggi yaitu Pengabdian kepada Masyarakat.

\section{KESIMPULAN DAN SARAN}

Kesimpulan yang dapat diambil dari kegiatan pengabdian kepada masyarakat kali ini adalah sebagai berikut:

1. Tim pelaksana pengabdian kepada masyarakat yang beranggotakan staf pengajar Jurusan Teknik Elektro Fakultas Teknik Universitas Mataram telah melaksanakan kegiatan pelatihan tentang rekayasa lampu $220 \mathrm{~V}$ menjadi $12 \mathrm{~V}$ dan penggunaan lampu $12 \mathrm{~V}$ untuk penerangan warga Dusun Buani, Desa Bentek, Kecamatan Gangga, Lombok Utara.

2. Warga Dusun Buani telah dapat mempraktekkan rekayasa lampu $220 \mathrm{~V}$ menjadi $12 \mathrm{~V}$ dan penggunaan lampu $12 \mathrm{~V}$ untuk penerangan jalan umum di Dusun Buani sehingga dapat memberikan manfaaat berupa peningkatan keamanan dan keselamatan bagi pengguna jalan di Dusun Buani pada saat malam hari.

3. Pelatihan yang telah dilakukan telah berhasil untuk memberikan tambahan pengetahuan kepada Dusun Buani mengenai kedua hal tersebut di atas sebagai bagian dari ilmu pengetahuan yang dimiliki oleh tim pelaksana kepada masyarakat untuk 
pemenuhan salah satu Tri Dharma Perguruan Tinggi yaitu Pengabdian kepada Masyarakat.

Saran untuk pengabdian pada masyarakat lebih lanjut agar pelatihan ini dapat dilakukan di lebih banyak tempat lagi agar lebih banyak warga yang dapat menguasai keahlian dari pelatihan ini sehingga bermanfaat bagi kepentingan warga masyarakat yang lainnya

\section{Ucapan Terima Kasih}

Penulis mengucapkan terima kasih kepada Kementerian Ristekdikti dan Lembaga Penelitian dan Pengabdian Pada Masyarakat Universitas Mataram yang telah memberi dukungan financial terhadap kegiatan pengabdian pada masyarakat ini.

\section{DAFTAR PUSTAKA}

BPMBD Provinsi NTB. 2016. Bentek lombokutara, http://bpmpd.ntbprov.go.id., diakses tgl 12 Februari 2019.

Sugeng. 2016. Daftar Nama Desa \& Dusun Di Kecamatan Gangga Kab. Lombok Utara, http://www.kecarat.com/p/blog-page.html, diakses tgl 12 Februari 2019.

Sandi, SB. 2016. Merubah Lampu LED 220 AC Ke 12 V DC, https://www.sandielektronik.com/2016/04/led-220v-menjadi-12v.html, diakses tgl 12 Februari 2019. 